\title{
Effectiveness of Transcranial Direct Current Stimulation on Depression and Anxiety in Methadone Consumers
}

Mahdi Naeim ( $\nabla$ m.naeim@arums.ac.ir)

Ardebil University of Medical Sciences https://orcid.org/0000-0003-4491-6160

\section{Sahar Aligholizadeh Moghadam}

Islamic Azad University Ardabil Branch

\section{Farzin Rezaei}

Iran University of Medical Sciences School of Behavioral Sciences and Mental Health

\section{Ali Rezaeisharif}

University of Mohaghegh Ardabili

\section{Research article}

Keywords:

Posted Date: October 10th, 2019

DOI: https://doi.org/10.21203/rs.2.15986/v1

License: (a) (i) This work is licensed under a Creative Commons Attribution 4.0 International License. Read Full License

Version of Record: A version of this preprint was published on June 1st, 2021. See the published version at https://doi.org/doi: 10.1097/ADT.0000000000000234. 


\section{Abstract}

Background: This research is aimed at Effectiveness of Transcranial Direct Current Stimulation on Depression and Anxiety in Methadone Consumers Methods: The research performed about the effect of electric TDCS on depression and anxiety caused by methadone consumption has not been paid attention. In this research, 40 people were studied as a group. These people took a test before and after the eight-day period of simulation. After the primary test, people received device simulation for 8 consecutive days on a specific time. Kolmogorov-Smirnov and Wilcoxon tests were used for analyzing the data. Results:The results show that with the score of 1.69 for the first variable, the patients' anxiety level is much lower at the time of electric simulation. Also, regarding the score of 1.62 in the second hypothesis, it can be stated that depression level was much lower at the time of performing the simulation. Conclusions: Regarding the fact that drug consumption is one of the most important health problems in the society, performing such projects will be useful. It needs to be mentioned that even according to the findings of this research, people who are intended to quit their addiction should be under treatment of addiction treatment and consultation centers to control their depression and anxiety in order to achieve the desired results.

\section{Background}

Per capita prevalence of depression among the addicts is about 50 to 60 percent and the prevalence of minor depressive disorder is about 10 percent. Also, per capita prevalence of addiction among the total patients with psychological disorders is about 29 percent and among the depressed patients referring to psychiatric clinics, it is about 56 percent (1). It is stated that 40 percent of the people who have drug abuse (opiate or non-opiate) have had a period in their lives in which they had the diagnostic criteria of major depressive symptom (2). Quality of life is considered as a valid scale for evaluating the outcome of the therapeutic and service methods provided for a damaged person (3). Quality of life includes the persons' physical health, psychological state, social relationships, religious and personal beliefs, and it is evaluated based on the persons' mental experiences (4). Researchers have shown that abuse of opiate drugs, calmatives, and alcohol is related to low quality of life. The results of the researches about the effect of methadone maintenance treatment on the addicts' psychological health are contradictory. For example, some research has shown that compared with the general population, the addicts under treatment by methadone have had a high level of psychological problems, and they have experienced most of the mood and emotional disorders such as depression and anxiety (5). In treatment with methadone, special centers deliver this drug to patients in the form of edible syrup and in a controlled way. From the experts' view, replacement of methadone can decrease the prevalence of injection addiction and dangerous diseases such as AIDS, and on the other hand, communication of the addicts with drug distributors is prevented and the probability of crime commitment is decreased (6). At the late 90s, a method called TDSC was introduced which invaded the nerve tissue by induction of electric current. In this method, anode electrode is connected to the considered point and, as a reference cathode electrode is connected on a point distant from the anode electrode. Electric current is directed from the anode electrode which is simulator to the cathode electrode which is inhibitory. TDSC is one of the newest methods of brain stimulation which has attracted attention for two reasons: being non-invasive and economically cheap. Also, this method with magnetic stimulation is considered as one of the harmless and non-seizure causing methods. In TDSC method, even a weak electric 
current enters the nerve tissue through the skin and cranium and changes the irritability of this tissue. The common used protocols of TDCS are related to two electrodes connected on the skin one of which works as anode and the other works as the cathode. An electric current of one to two $\mathrm{mA}$ is applied for 20 minutes between these two electrodes each of which usually have a cross section of $35 \mathrm{~cm}^{2}$. The direction of the current is from the cathode to the anode and depending on the direction and intensity of the current, irritability of the cerebral cortex is increased or decreased (7). According to what was stated, the main question of this research is whether TDCS has any effect on depression and anxiety caused by methadone consumption?

\section{Research Objectives}

\section{General objective}

The general objective is to determine the effect of TDCS on depression and anxiety caused by methadone consumption.

\section{Specific objectives}

Determining the effect of TDCS on depression caused by methadone consumption

Determining the effect of TDCS on anxiety caused by methadone consumption

\section{Research hypotheses}

TDCS affects the depression caused by methadone consumption.

TDCS affects the anxiety caused by methadone consumption.

\section{Methods}

The present research is a retrospective one (using the past information) and in terms of purpose, it is an applied research. In order to collect the research literature, library method has been used. in this descriptiveanalytical study which has been performed in a case manner in 2018,50 people have been studied as a group. After declaring their consent for cooperation, people filled the questionnaires. These people took a test before and after the stimulation period (in an eight-day period and on a specific time everyday). The research population includes 50 persons referring to addiction treatment centers of the city of Ardabil who are intended to quit their addiction and are consuming methadone by informing the center staff. This study 
was approved by the Institutional Review Board and Ethics Committee of Ardabil University of Medical Science and conducted in accordance with the principles laid down in the Declaration of Helsinki. After an in-depth explanation of the study's purpose and methods, written consent was obtained from all eligible patients and caregivers.

\section{Research procedure}

After getting a written consent letter and insuring the persons about the privacy of their information, questionnaires (which are available in the appendix) were filled. Beck's depression inventory whose reliability and validity had been measured in domestic studies was used. In the study performed by Dobson and Mohammad Khani, Cronbach's alpha coefficient was reported as 96 percent for this test. Beck's test includes 21 questions and four choices for each question. If the respondent chooses the first choice of all the questions, the resulted score will be zero, and if the person chooses the fourth choice of all the questions, the score will be 63. In this test, if the person gets a score of less than 16 , the result suggest no depression, for the scores of 17-25 the result if mild depression, for the scores of 26-33 the results if moderate depression, and for the scores of more than 34 the result if severe depression. For evaluating the anxiety, Berger's test was used whose reliability and validity was determined.

Also, all the subjects have an age range of 20 to 45 years old, and for controlling the gender, the research population has been selected from among the men. In order to prevent the effect of temperature and climatic conditions on further tiredness, all the tests are done in the evening. All the subjects are asked not to have any physical exercise for 24 hours before the test, and to have enough rest and sleep. The conditions of execution of the test were the same for all the subjects. All the subjects are healthy persons. For analyzing the data, descriptive and inferential statistics were used. In order to determine the normality of data distribution, in the part of descriptive statistics, mean and standard deviation were used and in the part of inferential statistics, Kolmogorov-Smirnov test was used, and significance level of alpha was considered as $5 \%$. In order to compare the levels of the severity of depression, Wilcoxon test was used. All the statistical studies were done by using SPSS20 and Excel (2016) software.

\section{Results}

Table1. Descriptive statistics of the research variables

The data included in table 1 shows The mean of TDCS (3.643), mean depression (3.515) and mean anxiety (3.623).

\section{Testing the normality of the data distribution}

In order to test the data normality, different method are used one of which is using the form of the distribution or in other words, calculating the skewness and kurtosis of the research variables. Researchers believe that whenever skewness and kurtosis of the data are between 2 and -2 , distribution of the variables is normal. In this research, Kolmogorov-Smirnov test is used to determine the normality of data distribution. 
In regression test, there is no need to normality of all the data, but the factors (structures) should be normal (8). Therefore, the assumption of normality of the data at the significance level of $5 \%$ has been tested by Kolmogorov-Smirnov test. For this test, statistical hypotheses are considered as the following:

In the first hypothesis:

$\mathrm{H}_{0}$ : TDCS affects the depression caused by methadone consumption.

$H_{1}$ : TDCS has no effect on depression caused by methadone consumption.

And in the second hypothesis:

$H_{0}$ : TDCS affects the anxiety caused by methadone consumption.

$\mathrm{H}_{1}$ : TDCS has no effect on anxiety caused by methadone consumption.

The results of the data normality test are presented in table 2 .

Table2. Data normality test

As presented in the above table, in all the cases, the significance value has been obtained more than 0.05 . Therefore, there is no evidence for rejecting the null hypothesis which suggests the normality of the data. In other words, distribution of the research data is normal and parametric tests can be executed.

\section{Information of Beck's test}

Table3. Score of Beck's test

The data included in table 3 shows that among the 40-year sample group who responded Beck's test, 25 people (62.5\%) got a score of 1 to 10,12 people (30\%) got a score of 11 to 16,2 people (5\%) got a score of 21 to 30 , and no one got the score of 40 or more.

\section{Information of Berger's inventory}

Table4. Scores of Berger's inventory

The data included in table 4 shows that among the 40-people sample group who responded Berger's inventory, 5 people (12.5\%) got a score of $20-31,7$ people (17.5\%) got a score of $32-42,22$ people $(55 \%)$ got a score of $43-53,3$ people (7.5\%) got a score of $54-64,2$ people (5\%) got a score of $65-75$, and only one person $(2.5 \%)$ got the score of 76 or more.

\section{Testing the research hypotheses}

Hypothesis1: TDCS affects the depression caused by methadone consumption.

For testing this hypothesis, $t$ significance test was used. The data included in table 5 shows suggest that at the significance level of $(\mathrm{sig}=0.000)$, the variables of TDCS and depression have a relationship $(r=0.615)$. It 
can be such analyzed that the correlation between the two variables is equal to 0.615 which is a good and strong correlation. The type of correlation between the two mentioned variables is direct (positive) and the significance level has been obtained as 0.000 . Since the significance value $(0.000)$ is less than the research alpha value (0.05), the relationship between the two variables is significant. So, the first research hypothesis is approved. As a result, it can be stated that there is a relationship between TDCS and depression caused by methadone consumption.

Table5. The relationship between TDCS and depression

Hypothesis2: TDCS affects the anxiety caused by methadone consumption.

The data included in table 6 shows suggest that at the significance level of $($ sig=0.05), the variables of TDCS and anxiety have a relationship $(r=0.643)$. It can be such analyzed that the correlation between the two variables is equal to 0.643 which is a good and strong correlation. The type of correlation between the two mentioned variables is direct (positive) and the significance level has been obtained as 0.000 . Since the significance value is less than the research alpha value (0.05), the relationship between the two variables is significant. So, this hypothesis is approved. As a result, it can be stated that TDCS affects the anxiety caused by methadone consumption.

Table6. Correlation test of the relationship between TDCS and anxiety

Table7. Variance analysis test for reviewing the respondents' viewpoints

The data included in table 7 shows there is a meaningful relationship between TDCS and anxiety and depression.

\section{Investigation of the research hypotheses by Wilcoxon test}

After the approval of the used scale, the data collected by Wilcoxon test was used for investigating the research hypotheses.

The first hypothesis: TDCS affects the depression caused by methadone consumption.

In the first hypothesis, the relationship between TDCS and depression is investigated. The value of the correlation between the two variables of TDCS and depression observed in the SPSS software output is equal to 0.615 according to table 8 . It suggests that correlation between these two variables has good and acceptable value. This test has been done at the significance level of $95 \%$. So, error level is equal to 0.05 , on in other words, error level is $a=5 \%$.

Table8. The effect of TDCS on depression

Also, by dividing the unstandardized beta coefficient by the standard error, the value of 9.352 is obtained which is larger than the critical value. Therefore, the observed beta coefficient is significant. The normal significance level is also less than the error level and it confirms the above mentioned finding. So, with a 
confidence level of $95 \%$, it can be said that there is a relationship between TDCS and depression caused by methadone consumption.

The second hypothesis: TDCS affects the anxiety caused by methadone consumption.

In the second hypothesis, the relationship between TDCS and anxiety is investigated. The value of the correlation between the two variables of TDCS and anxiety observed in the SPSS software output is equal to 0.610 according to table 9 . It suggests that correlation between these two variables has good and acceptable value. This test has been done at the significance level of $95 \%$. So, error level is equal to 0.05 , on in other words, error level is $a=5 \%$.

Table9. The effect of TDCS on anxiety

Also, by dividing the unstandardized beta coefficient by the standard error, the value of 9.359 is obtained which is larger than the critical value. Therefore, the observed beta coefficient is significant. The normal significance level is also less than the error level and it confirms the above mentioned finding. So, with a confidence level of $95 \%$, it can be said that there is a relationship between TDCS and anxiety caused by methadone consumption.

\section{Conclusions}

The results show that regarding the score of 1.69 for the first hypothesis, the level of patients' anxiety at the time consuming methadone is much lower than when they do not use methadone. Also, regarding the score of 1.62 for the second hypothesis, it can be said that their depression level at the time of consuming methadone is also much lower than when they do not use methadone. As a result, both the hypotheses are approved with a confidence of 95 percent. The results of this research are similar to the results of the researches performed by (9-16). Paying attention to depression and anxiety and the effect of TDCS on these variables in the addicts has a great importance. Therefore, the role of these stimulations in performance of the nervous system in different age groups, their effect on depression and anxiety, and especially on promotion of life quality is very significant. Although depression and anxiety usually simultaneously exist in people with drug addiction, the role of electric TDCS has been paid less attention in this, and sometimes, contradictory results have been reported by the researchers. However, for treating depression and anxiety, magnetic stimulations have been used more than electric stimulations, while electric stimulations are much cheaper and simpler and have lower risks(9). Nevertheless, research on the effect of electric TDCS on depression and anxiety caused by methadone consumption has not paid much attention. Regarding the fact that drug consumption is one of the most important health problems in the society, performing such projects will be useful. It needs to be mentioned that even according to the findings of this research, people who are intended to quit their addiction should be under treatment of addiction treatment and consultation centers to control their depression and anxiety in order to achieve the desired results. Most of these people are single and unemployed and they have about 5 to 10 years of drug consumption background. Such patients have mostly started their addiction with psychedelic pills and at the later stages, they prefer crystal drug to other drugs. The important point is that among the population of this research, most of them are educated persons with associate and bachelor degrees who are about 30 to 35 years old. However, after 
referring to addiction treatment centers, these people began to consume methadone under the control of the center staff. According to the results, their depression and anxiety level is much lower than the people who have not decided to quit their addiction yet.

\section{Declarations}

\section{Abbreviations}

TDCS: Transcranial Direct Current Stimulation

\section{Acknowledgements}

We would like to acknowledge the all participants in the study

\section{Authors' contributions}

MN, SAM, were the overall principal investigators for the study who conceived the study and , and they were responsible for study design and supervised the entire study. MN and SAM participated in the study design. AR and FR supervised the diagnosis of patients and subject recruitment. MN and AR performed statistical analyses. MN and SAM performed the experiments. FR supervised the experiments and data analyses. The manuscript was drafted by MN under the supervision of FR, who synthesized the manuscript. All authors critically reviewed the article and approved the final manuscript.

\section{Funding}

As a corresponding author , I confirm by the authors that there is no funding.

\section{Availability of data and materials}

All data generated or analysed during this study are included in this published article.

\section{Ethics approval and consent to participate}

This study was approved by the Institutional Review Board and Ethics Committee of Ardabil University of Medical Science and conducted in accordance with the principles laid down in the Declaration of Helsinki. After an in-depth explanation of the study's purpose and methods, written consent was obtained from all eligible patients and caregivers. 


\section{Consent to participate}

Informed consents were signed by the participants prior to data collection.

\section{Consent for publication}

Not applicable.

\section{Competing interests}

The authors declare no competing financial interests

\section{Author details}

1. Social Determinants of Health Research Center (SDH), Ardabil University of Medical Sciences, Ardabil, Iran

2. Department of Psychology, Ardabil Branch, Islamic Azad University, Ardabil, Iran

3. Psychiatric Research Center, Roozbeh Psychiatric Hospital, Tehran University of Medical Sciences

4. Department of Counseling, , University of Mohaghegh Ardebili.

5. Anahita Mental Health Center, Royan Ardebil Physicians Building

6. Health Research Center of Mohaghegh Ardabili University

7. Isar Psychiatric Hospital of Ardabil

8. Psychiatric ward of Fatemi hospital in Ardabil

\section{References}

1. Krantz MJ, Martin J, Stimmel B, Mehta D, Haigney MC. QTc interval screening in methadone treatment. Annals of internal medicine. 2009 Mar 17;150(6):387-95. DOI: 10.7326/0003-4819-150-6-20090317000103

2. Kaplan HI, Sadock BJ. Synopsis of psychiatry: Behavioral sciences clinical psychiatry. Williams \& Wilkins Co; 1988. https://doi.org/10.1097/00004850-198904000-00007

3. Wong JG, Cheung E, Chen EY, Chan RC, Law CW. An instrument to assess mental patients capacity to appraise and report subjective quality of life. Qual Life Res 2005; 14: 687-94.

https://doi.org/10.1007/s11136-004-1215-y 
4. Knotkova H, Rosedale M, Strauss SM, Horne J, Soto E, Cruciani RA, Malaspina D, Malamud D. Using transcranial direct current stimulation to treat depression in HIV-infected persons: the outcomes of a feasibility study. Frontiers in psychiatry. 2012 Jun 18;3:59. doi: 3389/fpsyt.2012.00059

5. Beck AT, Steer RA, Carbin MG. Psychometric properties of the Beck Depression Inventory: Twenty-five years of evaluation. Clinical psychology review. 1988 Jan 1;8(1):77-100. doi.org/10.1016/02727358(88) $90050-5$

6. Peles E, Schreiber S, Naumovsky Y, Adelson M. Depression in methadone maintenance treatment patients: rate and risk factors. Journal of affective disorders. 2007 Apr 1;99(1-3):213-20. doi.org/10.1016/j.jad.2006.09.017

7. Auvichayapat $P$, Keeratitanont $K$, Janyachareon $T$, Auvichayapat N. The effects of transcranial direct current stimulation on metabolite changes at the anterior cingulate cortex in neuropathic pain: a pilot study. Journal of Pain Research. 2018;11:2301. doi:10.2147/JPR.S172920.

8. Kalashloo, M., Rafeie, S., Baghshomali, S., Moghadam, S. A., \& Naeim, M. Stress Management Training Effects on Mental Health of Intellectual Disabilities Children Parents. Opción, 2018; 34, 133144.https://www.researchgate.net/publication/330010438 _Stress_Management_Training_Effects_on_Mental_Health_of_Intellectual_Disabilities_Children_Parents.

9. Knotkova H, Soto E, Leuschner Z, Greenberg A, Stock V, Das D, Cruciani R. Transcranial direct current stimulation (tDCS) for the treatment of chronic pain. The Journal of Pain. 2013 Apr 1;14(4):S64. doi:https://doi.org/10.1016/j.jpain.2013.01.592

10. Soler MD, Kumru H, Pelayo R, Vidal J, Tormos JM, Fregni F, Navarro X, Pascual-Leone A. Effectiveness of transcranial direct current stimulation and visual illusion on neuropathic pain in spinal cord injury. Brain. 2010 Aug 4;133(9):2565-77. doi: 10.1093/brain/awq184

11. Fecteau S, Agosta S, Hone-Blanchet A, Fregni F, Boggio P, Ciraulo D, Pascual-Leone A. Modulation of smoking and decision-making behaviors with transcranial direct current stimulation in tobacco smokers: a preliminary study. Drug and Alcohol Dependence. 2014 Jul 1;140:78-84. doi.org/10.1016/j.drugalcdep.2014.03.036

12. Xu J, Fregni F, Brody AL, Rahman AS. Transcranial direct current stimulation reduces negative affect but not cigarette craving in overnight abstinent smokers. Frontiers in psychiatry. 2013 Sep 20;4:112. https://doi.org/10.3389/fpsyt.2013.00112

13. Barr MS, Farzan F, Wing VC, George TP, Fitzgerald PB, Daskalakis ZJ. Repetitive transcranial magnetic stimulation and drug addiction. International Review of Psychiatry, 2011; 23(5), 454-466. doi.org/10.3109/09540261.2011.618827

14. Brunoni AR, Nitsche MA, Bolognini N, Bikson M, Wagner T, Merabet L, Edwards DJ, Valero-Cabre A, Rotenberg A, Pascual-Leone A, Ferrucci R. Clinical research with transcranial direct current stimulation (tDCS): challenges and future directions. Brain stimulation. 2012 Jul 1;5(3):175-95. doi: 10.1016/j.brs.2011.03.002.

15. Fregni F, Liguori P, Fecteau S, Nitsche MA, Pascual-Leone A, Boggio PS. Cortical stimulation of the prefrontal cortex with transcranial direct current stimulation reduces cue-provoked smoking craving: a 
randomized, sham-controlled study. Journal of Clinical Psychiatry. 2008 Jan 1;69(1):32-40. doi:10.4088/jcp.v69n0105

16. Wagner, T., Fregni, F., Fecteau, S., Grodzinsky. A., Zahn. M. \& PascualLeone. A. Transcranial Direct Current Stimulation: A Computer-based Human Model Study. Neuroimage. 2007; 19, 09, 11101124.https://doi.org/10.1016/j.neuroimage.2007.01.027

\section{Tables}

Table1. Descriptive statistics of the research variables

\begin{tabular}{|c|c|c|c|c|c|c|c|}
\hline Variable & Minimum & Maximum & Mean & $\begin{array}{c}\text { Standard } \\
\text { deviation }\end{array}$ & Variance & Skewness & Kurtosis \\
\hline TDCS & 1.500 & 4.833 & 3.643 & 0.591 & 0.349 & -0.462 & 0.364 \\
\hline Depression & 1.833 & 5.000 & 3.515 & 0.609 & 0.371 & 0.057 & -0.277 \\
\hline Anxiety & 1.800 & 5.000 & 3.623 & 0.691 & 0.477 & -0.169 & -0.145 \\
\hline
\end{tabular}

Table2. Data normality test

\begin{tabular}{|c|c|c|c|}
\hline Variable & KS value & Freedom degree & Status \\
\hline TDCS & 0.097 & 40 & Normal \\
\hline Depression & 0.068 & 40 & Normal \\
\hline Anxiety & 0.072 & 40 & Normal \\
\hline
\end{tabular}

Table3. Score of Beck's test

\begin{tabular}{|c|c|c|}
\hline Scores & Frequency & Frequency percentage \\
\hline $1-10$ & 25 & $62.5 \%$ \\
\hline $11-16$ & 12 & $30 \%$ \\
\hline $17-20$ & 1 & $2.5 \%$ \\
\hline $21-30$ & 2 & $5 \%$ \\
\hline 40 or more & 0 & $0 \%$ \\
\hline Total & 40 & $100 \%$ \\
\hline
\end{tabular}


Table4. Scores of Berger's inventory

\begin{tabular}{|c|c|c|}
\hline Scores & Frequency & Frequency percentage \\
\hline $20-31$ & 5 & $12.5 \%$ \\
\hline $32-42$ & 7 & $17.5 \%$ \\
\hline $43-53$ & 22 & $55 \%$ \\
\hline $54-64$ & 3 & $7.5 \%$ \\
\hline $65-75$ & 2 & $5 \%$ \\
\hline 76 or more & 1 & $2.5 \%$ \\
\hline Total & 40 & $100 \%$ \\
\hline
\end{tabular}

Table5. The relationship between TDCS and depression

\begin{tabular}{|c|c|c|}
\hline Variable & Statistical indicators & Scores \\
\hline \multirow{3}{*}{ TDCS } & Correlation coefficient & 0.615 \\
\cline { 2 - 3 } & Significance level & 0.000 \\
\cline { 2 - 3 } & The number of observation & 40 \\
\hline
\end{tabular}

Table6. Correlation test of the relationship between TDCS and anxiety

\begin{tabular}{|c|c|c|}
\hline Variable & Statistical indicators & Scores \\
\hline \multirow{3}{*}{ TDCS and anxiety } & Correlation coefficient & 0.643 \\
\cline { 2 - 3 } & Significance level & 0.000 \\
\cline { 2 - 3 } & The number of observation & 40 \\
\hline
\end{tabular}


Table7. Variance analysis test for reviewing the respondents' viewpoints

\begin{tabular}{|c|c|c|c|c|c|}
\hline & Sum of squares & Freedom degree & Mean Square & F & Sig \\
\hline \multirow{3}{*}{ TDCS } & 1.068 & 3 & 0.356 & \multirow{3}{*}{1.261} & \multirow{3}{*}{0.290} \\
\hline & 40.106 & 142 & 0.282 & & \\
\hline & 41.174 & 145 & 0.473 & & \\
\hline \multirow{3}{*}{ Depression } & 0.483 & 3 & 0.161 & \multirow[t]{3}{*}{0.611} & \multirow[t]{3}{*}{0.690} \\
\hline & 37.407 & 142 & 0.263 & & \\
\hline & 37.890 & 145 & 0.282 & & \\
\hline \multirow{3}{*}{ Anxiety } & 1.269 & 3 & 0.423 & \multirow{3}{*}{1.115} & \multirow{3}{*}{0.345} \\
\hline & 53.856 & 142 & 0.379 & & \\
\hline & 55.125 & 145 & 0.423 & & \\
\hline
\end{tabular}

Table8. The effect of TDCS on depression

\begin{tabular}{|c|c|c|c|c|c|}
\hline Variable & $\begin{array}{c}\text { unstandardized beta } \\
\text { coefficient }\end{array}$ & $\begin{array}{c}\text { Standard } \\
\text { error }\end{array}$ & $\begin{array}{c}\text { Standard beta } \\
\text { coefficient }\end{array}$ & VIII & $\begin{array}{c}\text { Normal } \\
\text { significance } \\
\text { value }\end{array}$ \\
\hline $\begin{array}{c}\text { TDCS and } \\
\text { depression }\end{array}$ & 0.641 & 0.069 & 0.615 & 9.352 & 0.000 \\
\hline
\end{tabular}

Table9. The effect of TDCS on anxiety

\begin{tabular}{|c|c|c|c|c|c|}
\hline Variable & $\begin{array}{c}\text { unstandardized beta } \\
\text { coefficient }\end{array}$ & $\begin{array}{c}\text { Standard } \\
\text { error }\end{array}$ & $\begin{array}{c}\text { Standard beta } \\
\text { coefficient }\end{array}$ & VIII & $\begin{array}{c}\text { Normal } \\
\text { significance } \\
\text { value }\end{array}$ \\
\hline $\begin{array}{c}\text { TDCS and } \\
\text { anxiety }\end{array}$ & 0.621 & 0.069 & 0.610 & 9.359 & 0.000 \\
\hline
\end{tabular}


Page 14/14 